munity and IUPAC and stated that the donation will be assigned to a specific activity at the Congress. Details about Macro2014 are online at www.macro2014.com.

\section{Thieme-IUPAC Prize 2014 Call for Nominations}

$\mathrm{T}$

he Thieme-IUPAC Prize is presented every two years on the occasion of the IUPAC International Conference on Organic Synthesis (IUPAC-ICOS). The ICOS-20 will be held in Budapest, Hungary, on 29 June-4 July 2014.

Sponsored jointly by Georg Thieme Verlag, IUPAC, and the editors of SYNLETT, SYNTHESIS, Science of Synthesis, and Houben-Weyl, the prize is awarded to a scientist under 40 years of age whose research has had a major impact in synthetic organic chemistry.

The prize is given on the basis of scientific merit for independent research dealing with synthesis in the broadest context of organic chemistry, including organometallic chemistry, medicinal and biological chemistry, designed molecules, and materials. Candidates must be under 40 years of age as of 1 January of the year in which the prize is awarded.

The Thieme-IUPAC Prize was awarded to Stuart L. Schreiber in 1992, Paul Knochel in 1994, Eric N. Jacobsen in 1996, Andrew G. Myers in 1998, Alois Fürstner in 2000, Erick M. Carreira in 2002, John F. Hartwig in 2004, David W. C. MacMillan in 2006, F. Dean Toste in 2008, Phil S. Baran in 2010, and Melanie S. Sanford in 2012.

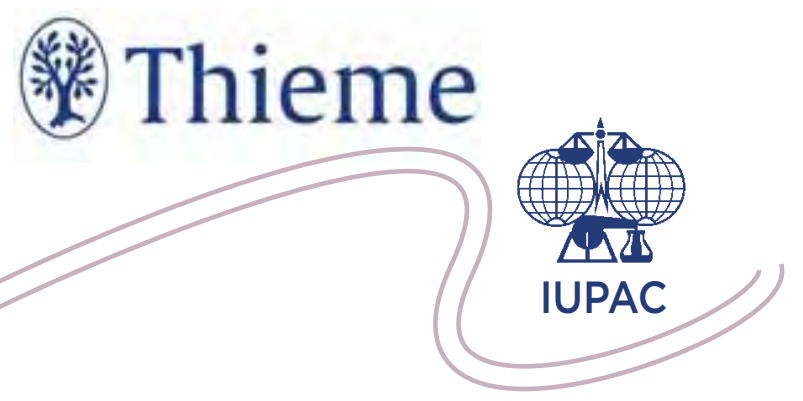

The 2014 Call for Nominations is now open. The Nominations Deadline is 13 December 2013.

www.thieme-chemistry.com/en/our-service/conferences/thieme-iupacprize/call-for-nominations.html

\section{Polymer International-IUPAC Award-Call for Nominations}

$\mathrm{T}$ he call for nominations for the 4th Polymer International-IUPAC Award for Creativity in Applied Polymer Science or Polymer Technology is now open. The deadline for entries is 31 October 2013. Readers of $\mathrm{Cl}$ are encouraged to recognize the achievements of their colleagues by nominating them for this award, which includes a cash prize of USD 5000.

The award will be presented at the IUPAC World Polymer Congress-MACRO 2014, 6-11 July 2014 in Chiang Mai, Thailand. The winner will be awarded USD 5000 plus travel and hotel accommodation expenses to attend MACRO 2014, where he/she will present an award lecture.

The winner will be selected by the Scientific Committee, representing Polymer International and the IUPAC Polymer Division. Nominees must be under age 40 on 31 December 2014 and must be available to present an award lecture at MACRO 2014. Please see website for specific details regarding the nomination process.

The Polymer International-IUPAC Award was awarded to Zhenan Bao in 2008, Molly Stevens in 2010, and Ali Khademhosseini in 2012.

Siin http://onlinelibrary.wiley.com/journal/10.1002/(ISSN)1097-0126/homepage/ polymer_internations_iupac_award.htm

\section{Research Integrity-The Montreal} Statement

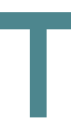

he 3rd World Conference on Research Integrity, held 5-8 May 2013 in Montreal, focused international attention on research integrity, responsible conduct of research, and publication of research. Attendees had opportunities to learn the current state of worldwide progress on research integrity, discussed new challenges and emerging topics, and helped shape national and international responses. 